\title{
Hydrolytic Enzymes of Human Blood Monocytes and Neutrophils with Special Reference to Lysozyme (Muramidase)
}

\author{
Hiroshi Ohta and Elliott F. Osserman \\ The First Department of Internal Medicine, Nagoya University \\ School of Medicine, Nagoya, Japan, and Institute of Cancer \\ Research, Columbia University and the Department of Medi- \\ cine, College of Physicians and Surgeons, New York, N.Y., \\ U.S.A.
}

OнTa, H. and Osserman, E.F. Hydrolytic Enzymes of Humxn Blood Monocytes and Neutrophils with Special Reference to Lysozyme (Muramidase). Tohoku J. exp. Med., 1972, 107 (3), 229-240 — In order to elucidate the cause of markedly increased serum and urine lysozyme (muramidase) in patients with monocytic leukemia on the cellular basis, monocytes and neutrophils were compared on their hydrolytic enzyme contents and their characteristics. Both types of leukocytes were separated from normal human blood or from patients with monocytic leukemia by means of floatation in dense albumin, utilizing the difference in the specific gravity of both cell types. Equivalent lysozyme and acid phosphatase activities were found to be present in monocytes and neutrophils and very low or negligible activities of alkaline phosphatase in monocytes. The subcellular distributions of these enzymes were comparable in the pattern and specific activity in both cell populations and found to be associated with granules. The phagocytic rate and the readiness of release of lysozyme into the extracellular medium during phagocytosis were similar in both cell populations. Leukemic leukocytes, neutrophils and monocytes, showed lower hydrolase activities than normal counterparts, especially alkaline phosphatase being markedly suppressed in leukemic cells. The possibility was discussed that the mechanism for elevated lysozyme in serum and urine of patients with monocytic leukemia may be accounted for by the developmental potential of monocytes in extravascular sites into macrophages with marked increase in lysosomal enzymes, the relatively ready release of lysozyme from cells, and a stable nature of lysozyme. ___ lysozyme (muramidase); leukocytes; neutrophils; monocytes

Markedly increased serum and urine lysozyme in patients with monocytic leukemia has been ascribed to overproduction of this protein because of proliferation and destruction of lysozyme-containing cells (Osserman and Lawlor 1966, Perillie et al. 1968). Subsequent to the original observation of Fleming (1922) and Fleming and Allison (1922) which established the relationship of leukocytes to lysozyme, identification of the particular population of leukocytes containing lysozyme has been the subject of several studies (Barnes 1940, Flanagan and Lionetti 1955, Brumfitt and Glynn 1961, Glynn and Parkman 1964, Briggs et al. 1966, 
Senn et al. 1970). Although granulocytes (neutrophils) and monocytes as well as tissue macrophagesare considered to elaborate lysozyme, relative lysozyme content in specific classes of leukocytes have remained to be clarified.

In order to make the quantitative study on lysozyme and other hydrolytic enzymes in leukocytes, an attempt was made to separate leukocytes obtained from peripheral blood of normal and monocytic leukemia subjects into specific classes and lysozyme and some other hydrolytic enzymes in such cell populations were studied.

\section{Materials and Methods}

Separation of monocytes and neutrophils

Fresh blood sample of normal person, usually one unit, was collected in bottles containing (ACD) as anticoagulant. Erythrocyte sedimentation was accelerated by addition of one-fifth the volume of $5 \%$ Dextran solution in saline (Dextran 250, molecular wieght up to 250,000, Pharmacia, Uppsala, Sweden). After one hour standing at room temperature, the upper leukocyte rich plasma was separated from the red cell layer and spun down in plastic tubes at $1,000 \mathrm{rpm}$ for $7 \mathrm{~min}$. The sedimented cells were washed twice with Krebs-Ringer phosphate buffer ( $\mathrm{pH}$ 7.3) (KRP) and suspended in the same buffer. For the separation of specific classes of leukocytes, that is, monocytes and neutrophils, the glass beads column method of Rabinowitz (1964) and the method of Bennet and Cohn (1966) by means of floatation in dense albumin were tested. The latter method was used mainly for the separation of monocytes, since the method gave a fairly good recovery of monocytes in a short period of time. After the second wash of leukocytes in $\mathrm{KRP}$, the packed cells were re-suspended in a small volume of KRP and was added with $35 \%$ alubmin (bovine, sterile, preservative-free, Pentex, Inc., Kankakee, Illinois) to give a final albumin concentration of $27 \%$ and cell concentration of $60-80 \times 10^{6} / \mathrm{ml}$. Ten milliliter aliquots were placed in lusteroid tubes and centrifuged in the swinging bucket rotor (HB-4 head, Servall centrifuge, Sorvall, Inc., Norwalk, Connecticut) at 2,400 $\times \mathrm{g}$ for $36 \mathrm{~min}$ at $12^{\circ} \mathrm{C}$. This yielded a compact pellet containing erythrocytes and neutrophils, and a waxy-appearing surface pellicle consisting largely of monocytes and of varying numbers of lymphocytes. The pellicles were removed with a small spatula and the cells were pooled in KRP. The pooled mononuclear cells were then collected by low speed centrifugation, followed by washing in KRP. The pellet fractions obtained by floatation in dense albumin and consisting of neutrophils and erythrocytes, were washed in KRP.

Stained smears were prepared on both the monocyte rich and neutrophil rich fractions with May-Giemsa stain (in order to obtain good stain, the cell suspensions were mixed with a small amount of own serum before being applied to slide glasses.). Total and differential countings of leukocytes were performed as usual. The recovery rate of monocytes and neutrophils ranged from 60 to $90 \%$. The cells were assayed for enzyme activities after 5 cycles of freezing and thawing.

Sucrose density gradient analysis of subcellular organelles of leukocytes

The monocyte rich and neutrophil rich fractions separated by the method described above were washed once in $0.25 \mathrm{M}$ sucrose-Tris $(\mathrm{pH} \mathrm{7.3)}$ and suspended in the same medium. The cells suspended at the concentration of $70-90 \times 10^{6} / \mathrm{ml}$ were homogenized for 4 min at 0 to $4^{\circ} \mathrm{C}$ with a motor-driven teflon pestle homogenizer. The grade of cell breakage was checked by a phase contrast microscopy. Two $\mathrm{ml}$ aliquots of the postnuclear supernatant fluid obtained after the centrifugation at $1,000 \times \mathrm{g}$ for $10 \mathrm{~min}$ were layered over $30 \mathrm{ml}$ of 30 to $70 \% \mathrm{w} / \mathrm{v}$ linear sucrose density gradient which was prepared using the Buchler density gradient system (Buchler Inst. Inc., New Jersey) by the method of Britten and Roberts (1960). The sucrose gradient samples were centrifuged in a SW 25.1 rotor of the 
Spinco model L2-65B centrifuge at $25,000 \mathrm{rpm}(63,581 \mathrm{~g}$ in average $)$ for 4 to 5 hours at $4^{\circ} \mathrm{C}$. After centrifugation the bottom of the tube was perforated with needle and 28-30 fractions were collected in tubes.

\section{Phagocytosis experiment}

This was performed in the cell suspension in KRP supplemented with own serum (final, 20\%) and with heat-killed Staphylococcus albus as particle to be ingested at a ratio of $10: 1$ in cell number in tubes. The tubes were incubated in $37^{\circ} \mathrm{C}$ water bath with constant shaking up to $45 \mathrm{~min}$ and aliquots were removed for enzyme analysis in extracellular medium. Cells which phagocytized bacilli were counted on the stained smear.

\section{Enzymatic studies}

Lysozyme was quantitated by the agar diffusion (lysoplate) method using purified human lysozyme as the standard, since human lysozyme has different activity from that of egg white lysozyme. 'Lyso-smear' method described by Briggs et al. (1966) was also adopted in some experiments.

Alkaline phosphatase was determined by the method of Bessey et al. (1946) using disodium $p$-nitrophenyl phosphate as substrate. One milliliter of $0.05 \mathrm{M}$ glycine- $\mathrm{NaOH}$ buffer ( $\mathrm{pH} 10.4)$ containing magnesium chloride $(0.5 \mathrm{mM})$ and substrate $(2 \mathrm{mg} / \mathrm{ml})$ was used as the substrate solution. The reaction was allowed to proceed for $30 \mathrm{~min}$ at $37^{\circ} \mathrm{C}$ and was terminated by the addition of $5 \mathrm{ml}$ of $0.02 \mathrm{~N} \mathrm{NaOH}$.

Acid phosphatase was determined in a $0.05 \mathrm{M}$ citric acid buffer ( $\mathrm{pH} \mathrm{5.0)}$ without magnesium, also using disodium $p$-nitrophenyl phosphate $(2 \mathrm{mg} / \mathrm{ml})$ as substrate, and terminating the reaction with 4 volumes of $0.1 \mathrm{~N} \mathrm{NaOH}$.

For the assay of both acid and alkaline phosphatases, the intensity of yellow color of $p$-nitrophenol liberated from the substrate was measured at $410 \mathrm{~m} \mu$ in a Zeiss PQM II spectrophotometer and units were defined as $\mu$ moles of $p$-nitrophenol liberated per hour.

Ribonuclease was measured by a modification of the procedure of Schneider and Hogeboom (1952) using highly polymerized calf thymus RNA (Calbiochem) as substrate $(0.7 \mathrm{gm}$ in $3.5 \mathrm{ml}$ of $0.05 \mathrm{M}$ sodium succinate buffer, $\mathrm{pH} 5.0$, containing $0.009 \mathrm{M} \mathrm{MgSO})$. After incubation at $37^{\circ} \mathrm{C}$ for $30 \mathrm{~min}$, the reaction was terminated with $1.2 \mathrm{ml}$ of $13.5 \%$ perchloric acid containing $0.25 \%$ uranyl acetate. After 1 hour at $4^{\circ} \mathrm{C}$, the mixture was centrifuged and the enzyme activity was expressed in terms of increase of optical density of the supernatant read at $260 \mathrm{~m} \mu$.

\section{Studies on the cells from patients with monocytic and other types of leukemia}

Blood samples of a 62-year-old negro male patient (P.M.) with monocytic leukemia were used for the study of the effect of phagocytosis on the liberation of lysozyme from monocytes and neutrophils as well as the study on the subcellular localization of hydrolytic enzymes in both types of cells. He took relatively mild course over a period of 2 years with moderate anemia (hemoglobin ranging $8.0-9.5 \mathrm{~g} / 100 \mathrm{ml}$ ) and leukocytosis up to $60,000 / \mathrm{cmm}$, mature monocytes occupying $40 \%$ and neutrophils $45 \%$ of total leukocytes. No chemotherapy had been instituted before the study was started.

Leukocytes from other 2 patients with monocytic leukemia having large number of mature monocytes capable of phagocytosis in peripheral blood were subjected to the separation of monocyte and neutrophil rich fractions.

Blood samples from patients with various types of leukemia were taken before chemotherapy. Regarding the acute myelocytic and lymphocytic leukemia, patients having more than $96 \%$ blast cells in the peripheral blood were selected for enzymatic studies. 


\section{Results}

Hydrolytic enzyme activities in leukocyte population

Peripheral blood leukocytes from 6 normal persons and 3 patients with monocytic leukemia were divided into monocyte rich and neutrophil rich fractions by means of centrifugation in dense albumin solution and assayed for hydrolytic enzyme activities. In Fig. 1 the enzyme activities assayed in monocyte rich and neutrophil rich fractions are plotted on the basis of percentage of monocytes and neutrophils, and the activities in the two fractions from the same subject are
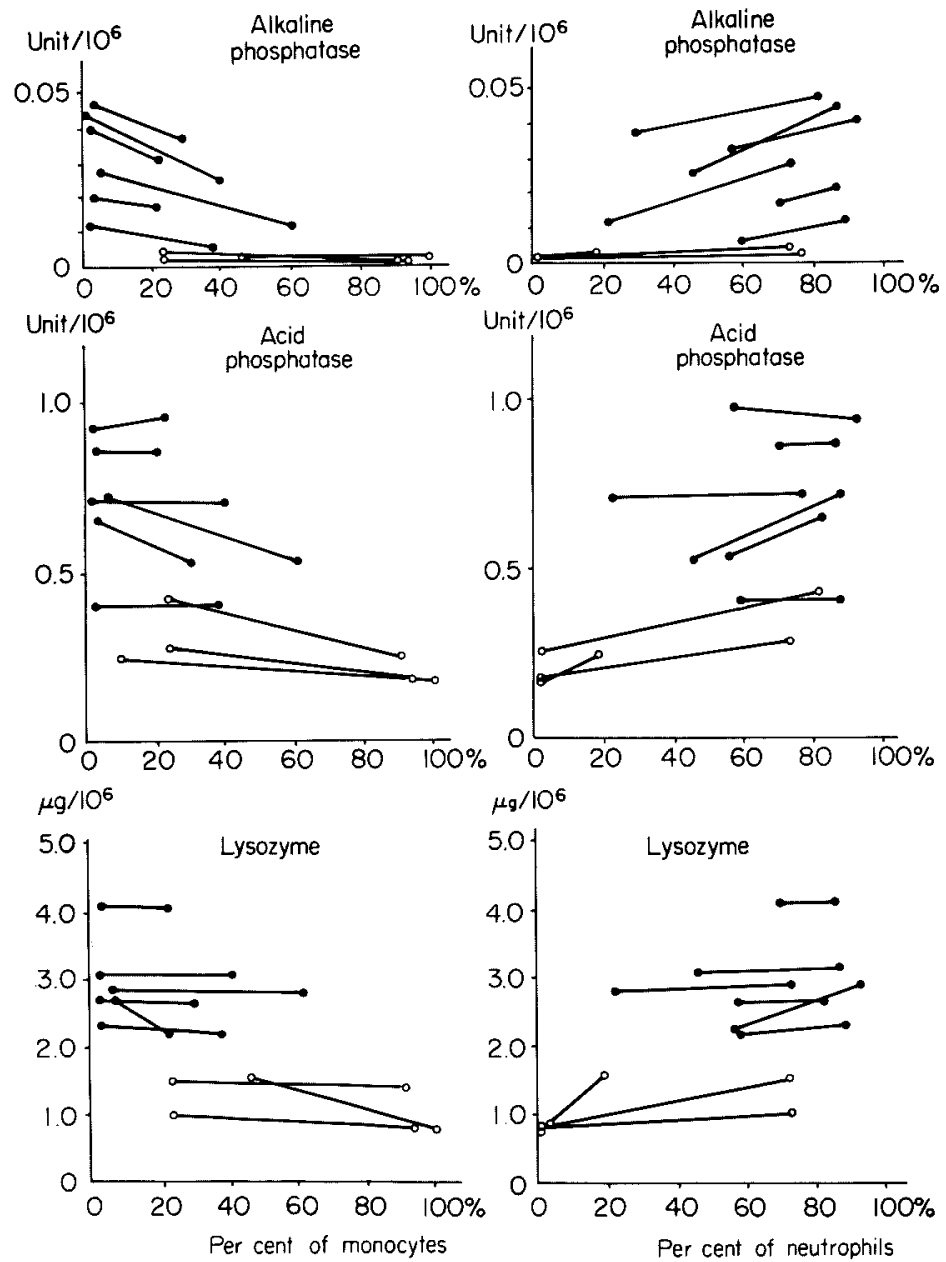

Fig. 1. Hydrolytic enzyme activities in monocytes and neutrophils. Enzyme activities are plotted according to the percentage of monocytes (left) and of neutrophils (right), and activities from the same source with varying proportion of monocytes or neutrophils are connected by solid line. Enzyme activities of normal leukocytes are expressed by solid circle and of leukemic leukocytes by open circle. 
connected by solid line. As the percentage of monocytes increases, equal or lower activities of lysozyme were observed in samples from normal person or monocytic leukemia (Fg. 1, left). Inversely, equal or higher lysozyme activities were observed in the neutrophil rich fraction (Fig. 1, right).

It is apparent, accordingly, that blood monocytes contain equivalent amount of lysozyme to neutrophils, assuming that other classes of leukocytes such as lymphocytes contain negligible amount of the enzyme as revealed by 'lyso-smear' observation or by the assay in pure lymphocyte suspension. Mean lysozyme content of normal monocytes was $3.0 \mu \mathrm{g} / 10^{6}$ cells, as compared to $3.2 \mu \mathrm{g} / 10^{6}$ of normal neutrophils. Monocytes and neutrophils from monocytic leukemia had the lysozyme activities of $1.8 \mu \mathrm{g} / 10^{6}$ cells and $2.2 \mu \mathrm{g} / 10^{6}$ cells, respectively.

Equivalent acid phosphatase activity was found in both monocytes and neutrophils. Neutrophils appeared to contain higher enzyme activity of alkaline phosphatase than monocytes since, as the percentage of monocytes increased the lower enzyme activity was observed. Monocytes and neutrophils from patients with monocytic leukemia had lower enzyme activities than normal counterparts, though the differences were not statistically significant except for very low value of alkaline phosphatase in leukemic leukocytes.

The lysozyme activity of surface pellicle cell fraction and pellet fraction of centrifuged tube increased as much as 4- to 6-fold when these fractions were subjected to physico-chemical treatments such as freezing and thawing, sonication and Triton X-100 treatment. Ribonuclease and acid and alkaline phosphatase activities also increased two to three times by these treatments. There was no difference in the extent of the enhancement of enzyme activities by such treatment in both monocyte rich and neutrophil rich fractions.

\section{Sucrose density gradient centrifugation of cellular organelles}

Postnuclear particulate fractions prepared from monocyte fraction (more than $90 \%$ purity) and neutrophil fraction (consisting of $95 \%$ neutrophils) which were separated by the method of floatation in dense albumin from a patient with monocytic leukemia (P.M.) were layered over a 30-70\% sucrose density gradient. Experiments were performed three times on the same patient with some intervals. The representative results of optical density at $280 \mathrm{~m} \mu$ and enzyme analysis are given in Fig. 2. Optical absorbancy curve at $280 \mathrm{~m} \mu$ gave one peak in the middle of the gradient and another one near the top layer of the gradient, though in some experiments a little shoulder after the main peak was noted, and all hydrolytic enzymes assayed were present correspondingly in the main peak region, that is, in particle fraction. The enzyme activities were low at top low-density layer, whereas more protein was detected in that layer than in the main peak region, when estimated by Folin's method (1927). Enzyme activities in the latter fractions increased by several times after physico-chemical treatments such as freezing and thawing, while the activities of enzymes present at the top layer were enhanced only slightly by such treatment. 

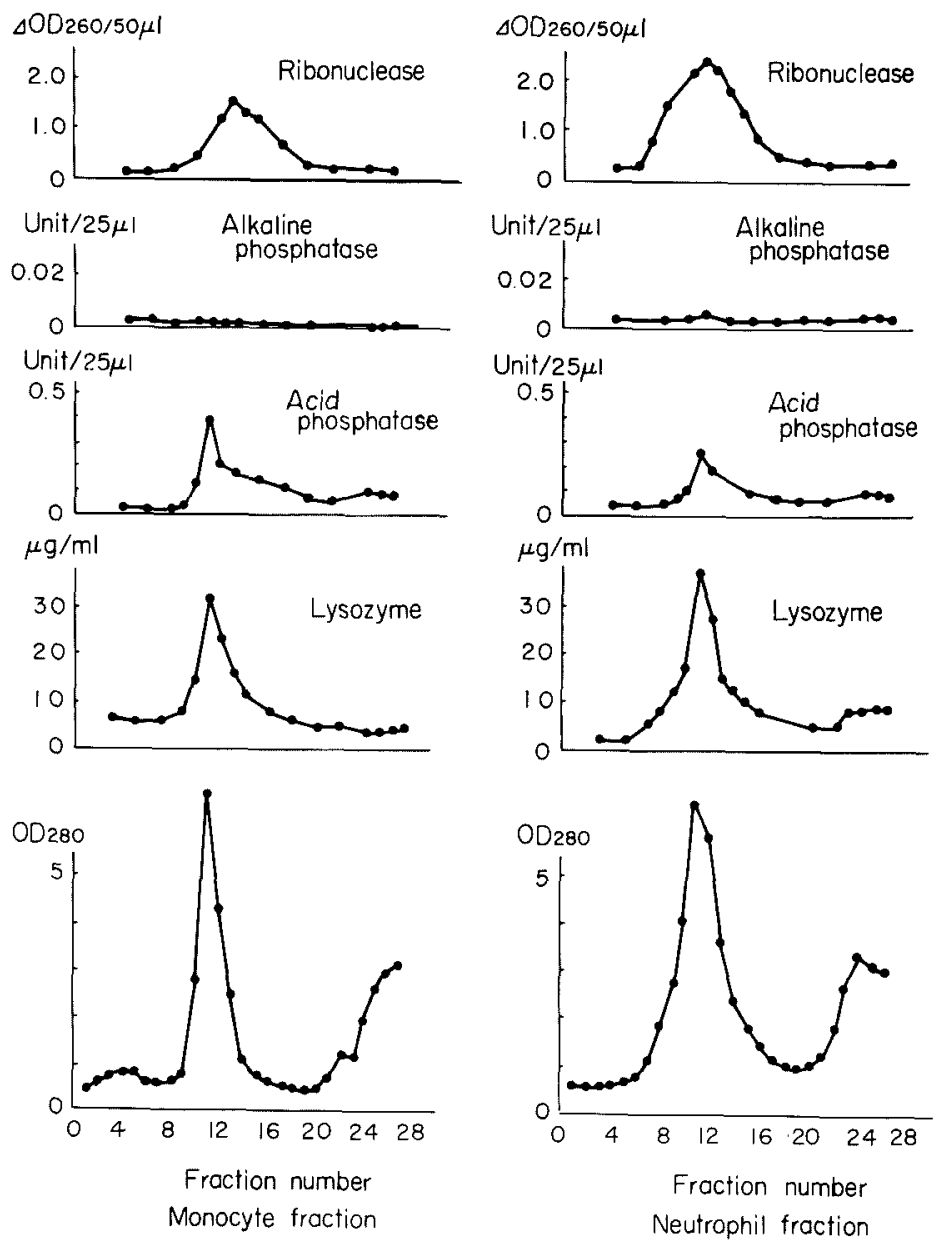

Fig. 2. Density equilibration of the postnuclear fraction of monocytes (left) and neutrophils (right) in a linear, aqueous sucrose density gradient. Fractions are numbered from the bottom (No. 1) to the top layer (No. 28-30).

No significant difference in the distribution pattern and in the specific activity of lysozyme was observed in the particulate fractions of monocytes and neutrophils. Activities of ribonuclease were higher in neutrophil fraction than in monocyte fraction, while no difference in activity of acid phosphatase was found in both fractions. Negligible activity of alkaline phosphatase was found in monocytes and very low activity in neutrophils.

Similar distribution pattern of hydrolytic enzymes was demonstrated in neutrophils purified from normal leukocytes by floatation in dense albumin solution.

\section{Phagocytosis by monocytes and neutrophils}

In view of the occasional presence of the vacuoles in cytoplasm of monocytes 

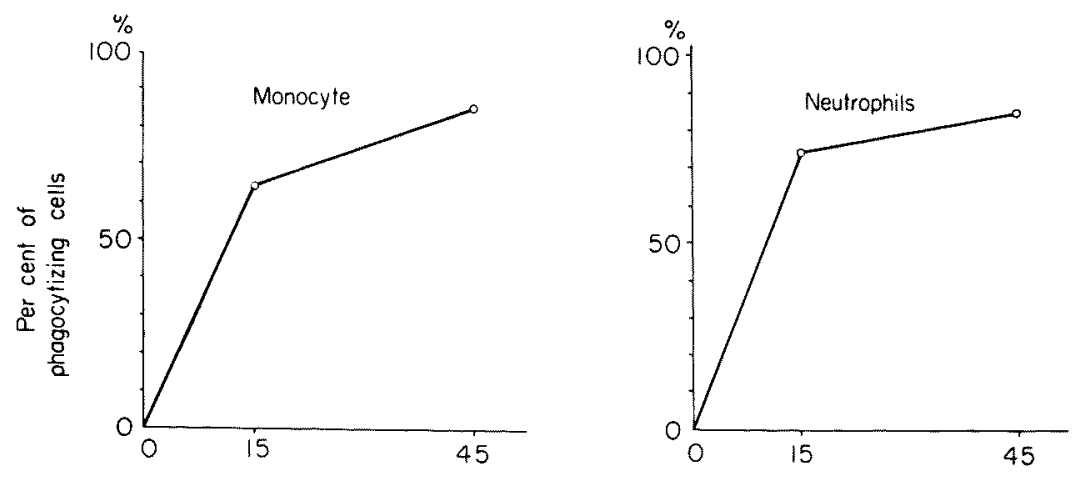

b

$\square$ Control
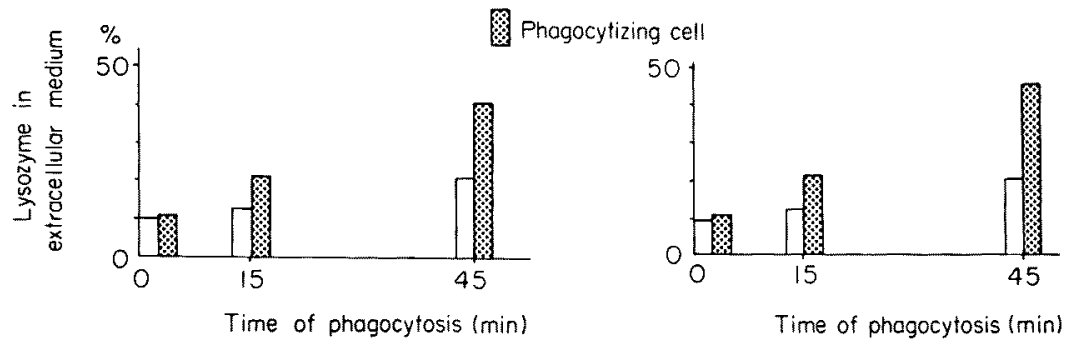

Fig. 3. Phagocytic rate of monocytes (upper left) and neutrophils (upper right), and the effect of phagocytosis upon the release of lysozyme into extracellular medium from monocytes (lower left) and neutrophils (lower right). Cells which ingested more than 2 bacilli were counted as phagocytizing cells.

after the separation by floatation in albumin solution, it may be conceived that monocytes have some different properties from neutrophils as to phagocytic activity and cell fragility. Fig. 3 shows the representative results of phagocytosis experiments with almost pure monocyte and neutrophil fractions obtained from a patient with monocytic leukemia (P.M.).

No difference was observed in the phagocytic rate between monocytes and neutrophils. Escape of cell-associated lysozyme into extracellular medium proceeded during the phagocytic event, without notable difference in the rate and extent of the release of lysozyme in both cell types.

Lysozyme content of leukocytes from normal persons and patients with various types of leukemia

As shown in Fig. 4, the greatest leukocyte lysozyme activity was found in normal subjects, and less activity in the following order: in leukocytes from patients with chronic myelocytic leukemia, monocytic leukemia, acute myelocytic leukemia, and negligible activity in acute and chronic lymphocytic leukemia. 


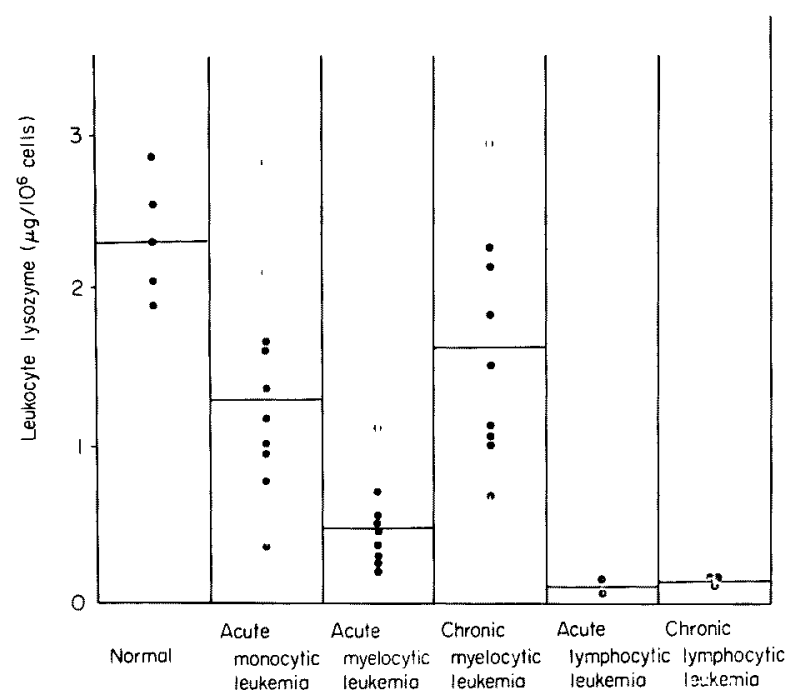

Fig. 4. Lysozyme activity in leukocytes from various types of leukemia.

\section{Discussion}

Attempts have been made to isolate specific population of leukocyte from peripheral blood as pure as possible and to compare the enzyme activities and other properties among these cells. Among the leukocyte classes, monocyte and neutrophil have some properties in common such as phagocytic activity etc., although the different biological function is postulated for respective cell types (cf. Leder 1967 for reference). The findings of high levels of serum lysozyme as well as marked lysozymuria in patients with monocytic leukemia have prompted the authors to examine whether mononuclear cells in such patients produce predominantly the lysozyme and whether other cells such as neutrophils also produce lysozyme in significant quantity.

Bennet and Cohn's method with centrifugation in albumin solution gave satisfactory results to obtain monocyte rich fraction, although sometimes it was difficult to obtain high percentage of monocyte population from normal blood. More than $90 \%$ monocyte population was attained with the peripheral blood of patients with monocytic leukemia. In order to get simple comparison, the detailed study was done on selected samples from 6 normal and 3 monocytic leukemia patients with a large number of mature monocytes out of a great number of blood samples from various types of leukemia.

Comparison of enzyme activity in the leukocytes consisting of varying proportions of leukocyte classes from the same person indicated the equivalent lysozyme activity in monocytes to that in neutrophils. The specific enzyme activity was almost the same in both cell types as shown by subcellular studies, though some degrees of lysozyme escape from monocytes during preparation could not completely be excluded in view of more extensive vacuolization found in these 
cells on the stained smear. This observation is similar to that of Briggs et al. (1966) made by an indirect histochemical technique. Senn et al. (1970) recently reported equivalent amounts of lysozyme in neutrophils and monocytes, though their values were somewhat higher than the values in this paper and this is possibly due to their use of egg white lysozyme as the standard in the enzyme assay. The activities of ribonuclease and alkaline phosphatase were higher in neutrophils than in monocytes.

When the enzyme activities were compared between normal and monocytic leukemia samples, the activities of hydrolytic enzymes were lower in monocytes and neutrophils from leukemic patients than those in normal counterparts, though these differences were statistically insignificant except for alkaline phosphatase.

The distribution pattern of lysozyme and hydrolase-containing particles in the cells were similar in both monocytes and neutrophils from monocytic leukemia and also in neutrophils from normal subjects. Their activities were enhanced by freezing and thawing, indicating the particle bound nature (latency).

The elevated lysozyme in serum does not appear to be due to the enzyme which was originally produced in other kinds of cells and then attached or ingested to neutrophils, since no significant increase could be observed in cellular lysozyme content when neutrophils from normal person having low serum lysozyme level were incubated with high level of lysozyme in vitro up to 16 hours.

Phagocytosis experiment showed no difference in the fragility of cells and readiness of escape of particle-bound enzymes into extracellular medium in both monocytes and neutrophils during the $45 \mathrm{~min}$ of incubation.

Although peripheral blood leukocytes from normal subjects and from patients with chronic myelocytic leukemia or monocytic leukemia consist of mixed cell populations, the data presented in Fig. 4 may not be incompatible with the findings in this report that neutrophils had higher or equal lysozyme content as compared to blood monocytes. The least enzyme activity was found in immature blast cells and also negligible lysozyme activity in lymphocytes. This was confirmed by the immunofluorescence method using monospecific antibody against human lysozyme; by this method the intensely positive fluorescence was found in neutrophils and monocytes, and weakly positive reaction in immature cells.

Various views have been presented to account for the almost constantly elevated serum lysozyme level and lysozymuria in monocytic leukemia, while in chronic myelocytic leukemia such findings were far less often and to less extent. Perillie et al. (1968) speculated that the possible mechanism may be the greater turnover of the leukemia cells in monocytic disorders and/or ready secretion or loss of intracellular lysozyme by monocytes than in leukemic cells of granulocytic disorders. However, the release of intracellular lysozyme from blood monocytes and/or neutrophils may not sufficiently account for the elevated lysozyme in serum and urine, since we did not observe the excretion of large quantities of lysozyme in urine of patients with chronic myelocytic leukemia by daily assay, while the patients continued to excrete uric acid massively during the course of intensive 
chemotherapy.

Although the lysozyme contents in blood monocytes and neutrophils were comparable, the developmental potential and functional capacity of monocytes, especially in extravascular sites, should be considered (Lewis 1925, Ungar, Jr. and Wilson 1935, Ebert and Florey 1939, Weiss and Fawcett 1953, Rabinowitz and Schrek 1962, Volkman and Gowans 1965 a, b, Pinkett et al. 1966). Hydrolase activities in blood monocytes and also peritoneal or alveolar mononuclear cells have been shown to increase during cell culture (Cohn and Benson $1965 \mathrm{a}, \mathrm{b}$, Bennet and Cohn 1966, Heise and Myrvik 1967), as compared to those in the neutrophils without such developmental capability. Schmalzl et al. (1969) recently reported that the early exudation of monocytes appeared as a specific feature of monocytic leukemia and that transformation of monocytoid cells to typical macrophages with an increase of the lysosomal enzymes occurred with enzyme activities remaining lower in this type of leukemia than in normals. We also observed increase in lysozyme activity in tissue macrophages in normal and monocytic leukemia subjects by means of immunofluorescent technique coupled with antibody against human lysozyme (Ohta et al. 1972). In granulocytic leukemia, however, it was reported that, despite the presence of many blasts, promonocytes, myelocytes and metamyelocytes in the blood, induced exudates contained segmented neutrophils and bands, and except for occasional metamyelocytes, immature cells did not appear therein (Boggs 1960, Perillie and Finch 1960, Tornyos 1967, Wulff 1967).

Therefore, immigratory capacity into tissues and developmental potential of monocytes in extravascular sites into macrophages with marked increase in lysosomal enzymes, together with the ready release of lysozyme from cells and stable nature of the enzyme would be very important factors for large quantity of lysozyme present in serum and urine of patients with monocytic leukemia, whereas the lysozyme content in blood monocytes and neutrophils were of the similar order. Another important factor in the cause of marked lysozymuria in monocytic leukemia would be the renal impairment. Pruzanski and Platts (1970) recently reported the combined glomerular-tubular dysfunction as a manifestation unique to this type of leukemia.

Added in proof We recently found that mononuclear cells in skin window exudates began to release the intracellular lysozyme earlier (at $7 \sim 10$ hours after making skin abrasion) than neutrophils which retained the enzyme until late (up to $36 \sim 48$ hours).

\section{Acknowledgment}

A part of this work was supported by USPHS Grant CA-02332. We wish to thank Mrs. Roberta Liblit for her excellent technical assistance. 


\section{References}

1) Barnes, J.M. (1940) The enzymes of lymphocytes and polymorphonuclear leukocytes. Brit. J. exp. Path., 21, 264-275.

2) Bennett, W.E. \& Cohn, Z.A. (1966) The isolation and selected properties of blood monocytes. J. exp. Med., 123, 145-160.

3) Bessey, O.A., Lowry, O.H. \& Brock, M.J. (1946) A method for the rapid determination of alkaline phosphatase with five cubic millimeters of serum. J. biol. Chem., 164, 321-329.

4) Boggs, D.R. (1960) The cellular composition of inflammatory exudates in human leukemias. Blood, 15, 466-475.

5) Briggs, R.S., Perillie, P.E. \& Finch, S.C. (1966) Lysozyme in bone marrow and peripheral blood cells. J. Histochem. Cytochem., 14, 167-170.

6) Britten, R.J. \& Roberts, R.B. (1960) High-resolution density gradient sedimentation analysis. Science, 131, 32-33.

7) Brumfitt, W. \& Glynn, A.A. (1961) Intracellular killings of micrococcus lysodeikticus by macrophages and polymorphonuclear leukocytes: a comparative study. Brit. J. exp. Path., 42, 408-423.

8) Cohn, Z.A. \& Benson, B. (1965a) The differentiation of mononuclear phagocytes. Morphology, cytochemistry, and biochemistry. J. exp. Med., 121, 153-170.

9) Cohn, Z.A. \& Benson, B. (1965b) The in vitro differentiation of mononuclear phagocytes. II. The influence of serum on granule formation, hydrolase production, and pinocytosis. J. exp. Med., 121, 835-848.

10) Ebert, R.H. \& Florey, H.W. (1939) The extravascular development of the monocyte observed in vivo. Brit. J. exp. Path., 20, 342-356.

11) Flanagan, P. \& Lionetti, F. (1955) Lysozyme distribution in blood. Blood, 10, 497501.

12) Fleming, A. (1922) On remarkable bacteriolytic element found in tissues and secretions. Proc. roy. Soc. $B, 93,306-317$.

13) Fleming, A. \& Allison, V.D. (1922) Observations on a bacteriolytic substance ("Iysozyme") found in secretions and tissues. Brit. J. exp. Path., 3, 252-260.

14) Folin, O. \& Ciocalteu, V. (1927) On tyrosine and tryptophane determinations in proteins. J. biol. Chem., 73, 627-650.

15) Glynn, A.A. \& Parkman, R. (1964) The distribution of cell lysozyme. III International Symposium on Flemings lysozyme, Milan.

16) Heise, E.R. \& Myrvik, Q.N. (1967) Secretion of lysozyme by rabbit alveolar macrophages in vitro. J. Reticuloendothel. Soc., 4, 510-523.

17) Leder, L. (1967) Blutmonozyten, Springer-Verlag, Berlín.

18) Lewis, M.R. (1925) The formation of macrophages, epithelioid cells, and giant cells from leucocytes in incubated blood. Amer. J. Path., 1, 91-100.

19) Ohta, H., Kamiya, O. \& Nagase, H. (1972) Blood monocytes and macrophages. Kinetic study with radioisotopes and cytochemical methods. Recent Advances in RES Research, 11 in press.

20) Osserman, E.F. \& Lawlor, D.P. (1966) Serum and urinary lysozyme (muramidase) in monocytic and monomyelocytic leukemia. J. exp. Med., 124, 921-952.

21) Perillie, P.E. \& Finch, S.C. (1960) The local exudative cellular response in leukemia. J. clin. Invest., 39, 1353-1357.

22) Perillie, P.E., Kaplan, S.S., Lefkowitz, E., Rogaway, W. \& Finch, S.C. (1968) Studies of muramidase (lysozyme) in leukemia. J. Amer. med. Ass., 203, 317-322.

23) Pinkett, M.O., Cowdrey, C.R. \& Nowell, P.C. (1966) Mixed hematopoietic and pulmonary origin of "alveolar macrophages" as demonstrated by chromosome markers. Amer. J. Path., 48, 859-867.

24) Pruzanski, W. \& Platts, M.E. (1970) Serum and urinary proteins, lysozyme (muramidase), and renal dysfunction in mono- and myelomonocytic leukemia. J. clin. Invest., 49, 1694-1708. 
25) Rabinowitz, Y. \& Schrek, R. (1962) Studies of cell source of macrophages from human blood in slide chambers. Proc. Soc. exp. Biol. Med. (N.Y.), 110, 429-431.

26) Rabinowitz, Y. (1964) Separation of lymphocytes, polymorphonuclear leukocytes and monocytes on glass columns, including tissue culture observations. Blood, 23, 811828.

27) Schmalzl, F., Huber, H., Asamer, H., Abbrederis, K. \& Braunsteiner, H. (1969) Cytochemical and immunohistologic investigations on the source and the functional changes of mononuclear cells in skin window exudates. Blood, 34, 129-140.

28) Schneider, W.C. \& Hogeboom, G.H. (1952) Intracellular distribution of enzymes. $\mathrm{X}$. Desoxyribonuclease and ribonuclease. J. biol. Chem., 198, 155-163.

29) Senn, H.J., Chu, B., O'Malley, J. \& Holland, J.F. (1970) Experimental and clinical studies on muramidase (lysozyme). I. Muramidase activity of normal human blood cells and inflammatory exudates. Acta haemat. (Basel), 44, 65-77.

30) Tornyos, K. (1967) Phagocytic activity of cells of the inflammatory exudate in human leukemia. Cancer Res., 27, 1756-1759.

31) Ungar, J., Jr. \& Wilson, G.R. (1935) Monocytes as a source of alveolar phagocytes Amer. J. Path., 11, 681-692.

32) Volkman, A. \& Gowans, J.L. (1965a) The production of macrophages in the rat. Brit., J. exp. Path. 46, 50-61.

33) Volkman, A. \& Gowans, J.L. (1965b) The origin of macrophages from bone marrow in the rat. Brit. J. exp. Path., 46, 62-70.

34) Weiss, L.P. \& Fawcett, D.W. (1953) Cytochemical observations on chicken : monocytes, macrophages, and giant cells in tissue culture. J. Histochem. Cytochem., 1, 4765.

35) Wulff, H.R. (1967) Morphological and Histochemical Features of Leucocytes in Experimental Inflammation and in Disease. Munksgaard, Copenhagen. 